\title{
A Systemic Approach Integrating Genetic, Mining and Management Visions: The Geologic and Mining Knowledge System
}

\author{
Nassareddine Azzouzi \\ Natural Resources and Environment Laboratory, Sidi Mohamed Ben Abdellah University, Polydisciplinary Faculty of Taza, \\ Taza, Morocco \\ Email: nassareddine.azzouzi@usmba.ac.ma
}

How to cite this paper: Azzouzi, N. (2017) A Systemic Approach Integrating Genetic, Mining and Management Visions: The Geologic and Mining Knowledge System. Journal of Geographic Information System, 9, 390-401.

https://doi.org/10.4236/jgis.2017.93024

Received: May 17, 2017

Accepted: June 24, 2017

Published: June 27, 2017

Copyright $\odot 2017$ by author and Scientific Research Publishing Inc. This work is licensed under the Creative Commons Attribution-NonCommercial International License (CC BY-NC 4.0). http://creativecommons.org/licenses/by-nc/4.0/

\begin{abstract}
Following the example of other industrial activities, mining evaluation is now exposed to socio-economical and technological constraints which are unstable in quick evolution. The keys to its success are increasingly related to a methodology of work more scientific than ever. The Systemic Approach has broadly showed its effectiveness in numerous disciplinary fields, both scientific and engineering ones: Biology, Economy, Social and Management Sciences, Quality Management, Information Systems... Helped by technological progress, this approach has especially excelled in the management of spatial information (e.g. GIS). It constitutes therefore an excellent solution to the problems of mining evaluation by the integration of genetic, mining and managerial data within an Information System, thus optimizing scientific and economic valuation of mineral resources.
\end{abstract}

\section{Keywords}

Mining Evaluation, Scientific Approach, Systemic Approach,

Geologic and Mining Knowledge System, Moroccan Context

\section{Introduction}

In response to socio-economic, environment and market constraints and in order to achieve the ultimate goal: the scientific and economic valuation of the geologic and mining resources, a general framework for a Systemic Approach integrating the aspects of the genetic characterization into those of the mining management is proposed.

This paper is justified by the recent awareness of Moroccan operators to the 
problems of mining evaluation ${ }^{1}$, which are well defined and characterized by the guide to the evaluation of gold deposits [1]. The paper aims, then, to build an integrated model of the keys to the success of the mining valuation. Such model will integrate the proposed Systemic Approach to the keys to the success of the mining evaluation process, synthesized from the quoted guide.

\section{Problems of Mining Valuation}

\subsection{The Moroccan Context}

Within its new unstable and dynamic competitive environment, Morocco should no longer rely on the significant amount of resources and reserves at its disposal. At the present time, the criteria for quality of ore mined and sold are not only the grade and the availability of large tonnages, as shown by the phosphate example [2]. With the new uses of phosphates in many fields of high technology and strong added value [3], with the diversification of ore processing [4] and with the ore prices volatility, requirements of clients were broadly diversified in terms of specifications: such as impurities content [5] [6]. The prospector's work is thus complicated by many new exploitability, marketability and profitability criteria that differentiate suppliers. The genetic (scientific) understanding of the ore becomes then a determining factor for its valuation [2]. For that purpose, the $\mathrm{OCP}^{2}$ Group, Moroccan state company and global leader in the phosphate industry, has, in fact, internally deployed a geological data processing system [7]. However, it is quite disappointing to note that the OCP still has a completely data closed policy and has never published about effectiveness and performance of its system.

On the other hand, like many developing countries, Morocco has designed for hydrocarbon and other mineral resources a proactive strategy of mining and oil valuation. This strategy initiated for more than a decade hoped to attract massive foreign investment to explore and develop national mining projects. From the structural, legal and promotional point of view some progress can be noted: 1) more attractive mining and hydrocarbon laws, 2) merger and restructuring of national mining $\left(\mathrm{BRPM}^{3}\right)$ and oil $\left(\mathrm{ONAREP}^{4}\right)$ promoting agencies into one agency $\left(\mathrm{ONHYM}^{5}\right)$ with more rationalized resources and more ambitious strategy, 3) effective actions of ONHYM... However, the management of knowledge (data and surveys) remains rudimentary: 1) insufficient carried out studies, 2) still partial cartographic coverage and at its best scale: $1 / 50,000,3)$ excessively rigid policy of sharing knowledge (too bureaucratic for investors and almost missing for researchers) and 4) the implementation of geologic and exploration GIS for data and knowledge management, both within ONHYM and the Ministry, was not really effective. There is nothing comparable to what occurs in some

${ }^{1}$ Please do not confuse: valuation and evaluation.

${ }^{2}$ OCP: Office Chérifien des Phosphates-http://www.ocpgroup.ma

${ }^{3}$ BRPM: Bureau de Recherches et de Participations Minières

${ }^{4}$ ONAREP: Office National de Recherche et d'Exploitations Pétrolières

${ }^{5}$ ONHYM: Office National des Hydrocarbures et des Mines-http://www.onhym.com/ 
countries that are leaders in data management: the $\mathrm{BGS}^{6}$, for example, has developed an effective knowledge management through an integrated Information System, and an effective knowledge exchange through a Workflow-based Cyber-Infrastructure [8] [9]. There would be no doubt that such a policy of information management, adopted by Morocco, has induced a negative impact on its mining promotion and valuation.

\subsection{The Mining Evaluation Characterization}

Thirty years ago, the still invaluable guide to the evaluation of gold deposits [1] characterized mining evaluation by 1) a high financial risk factor, 2) the complexity of its process, 3 ) the multiplicity of involved resources (Figure 1) and subdisciplines (Figure 2) and 4) the variability of its geological contexts (Figure 1). These fishbone diagrams show the tree of causes to effects of the mining success. Figure 1 details the key factors structure for a successful exploitation. In particular, it shows that the understanding of different geological contexts contributes alongside the factors related to the management of resources. Figure 2 details the key factors structure for a successful mining development project, where economic and financial factors, mining operations factors and mining reconnaissance factors are represented at the same level of the tree. Among causes of failure of mining evaluation which were quoted in the guide, those related to: 1) shortcomings of management (imperfect strategies and procedures...) and 2) shortcomings of knowledge (inappropriate skills, imperfect studies...).

Moreover, the guide underlined the iterative, probabilistic and gradually quantitative character of mining evaluation, making the calculation of realistic

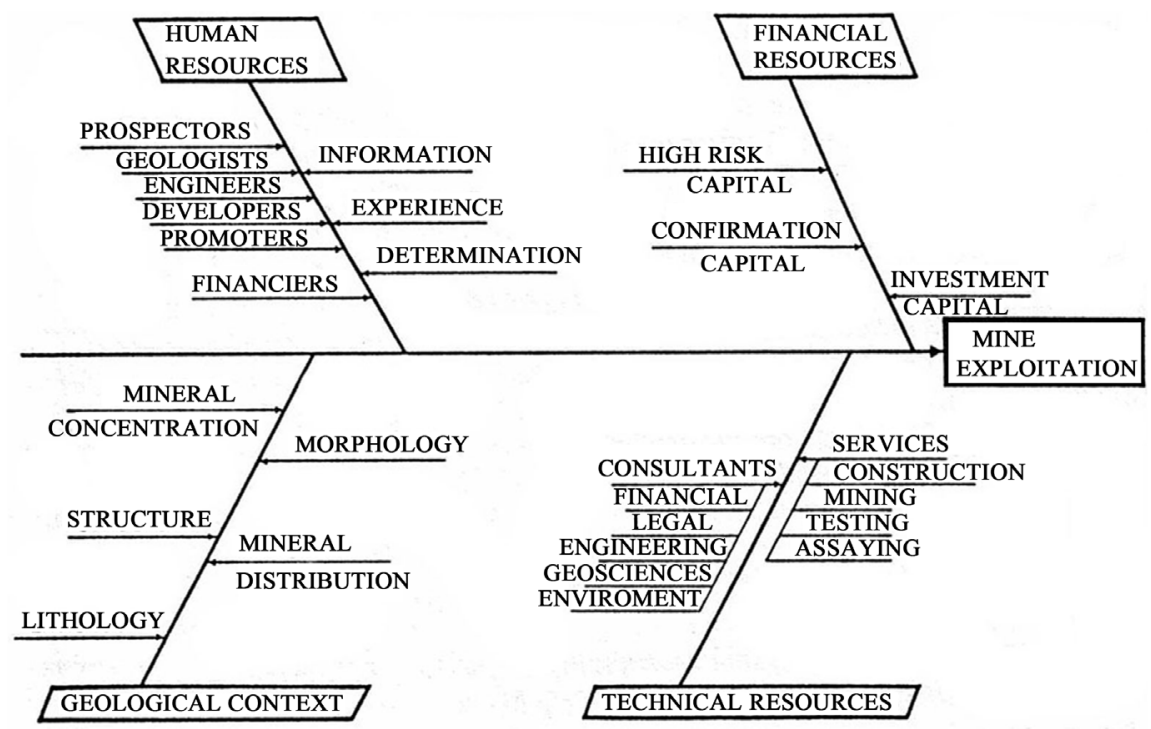

Figure 1. Causes (resources, geological context) to effects (exploitation success) diagram, by Vallée et al. [1]. ${ }^{7}$

${ }^{6}$ BGS: British Geological Survey-http://www.bgs.ac.uk.

${ }^{7}$ Printed in CIM Bulletin, Vol, 45, 1990. Reproduced with permission from the Canadian Institute of Mining, Metallurgy and Petroleum (CIM)-http://www.cim.org/. 


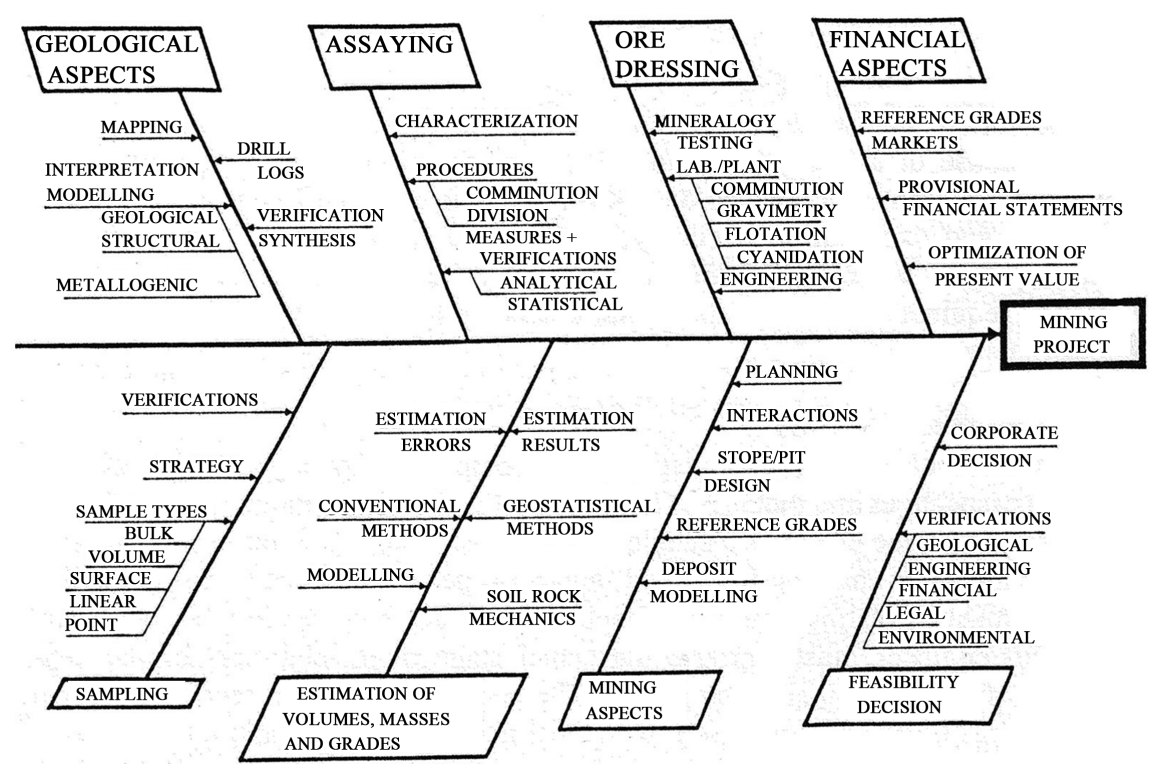

Figure 2. Causes (involved subdisciplines) to effects (mine development success) diagram, by Vallée et al. [1]. ${ }^{8}$

margins of errors (precision and accuracy) vital for any estimate and any modeling in relation to the decision processes. Thus, this guide clearly highlighted the necessity of the scientific approach for data acquisition, organization and processing in order to optimize the genetic and mining characterization.

Subsequently, the guide introduced the concept of the search for quality, 1) first by the need to accompany the whole process of mining evaluation by systematic procedures of control and verification, 2) next by the gradual guidance towards implementation of Continuous Improvement Systems, Total Quality Management Systems (TQMS), then the Systemic Approach, and ultimately, Multicriteria Decision Systems. Also note that the guide has already brought a set of recommendations and warnings on the use of new information technologies (NIT), principal ones would be the benefits of integration and the dangers of the automation of interpretation and decision.

In the same way, a survey that has determined skills needed by the NorthAmerican oil geologists [10], has confirmed the prevalent place of sciences which try to explain the genesis of hydrocarbons (like sedimentology and stratigraphy) compared to technical subdisciplines (such as geophysical, geochemical and mapping methods). This study has also shown the importance of information technologies as tools of assistance to interpretation and decision processes in addition to their benefits for data organization and presentation. However, the survey puts them in a secondary position compared to the geological profile (scientific and technical) proving that interpretation and decision still remain the specificity of the human intelligence.

${ }^{8}$ Printed in CIM Bulletin, Vol, 45, 1990. Reproduced with permission from the Canadian Institute of Mining, Metallurgy and Petroleum (CIM)-http://www.cim.org/. 


\subsection{The Keys to Successful Mining Valuation}

So, we will summarize the keys to the success of mining evaluation, in accordance with the approach of the guide to the evaluation of gold deposits [1], by highlighting the contribution of the genetic and managerial aspects beside the mining aspects (Figure 3), then by adding the contribution of the integrated aspects of the TQMS. The TQMS should embed, at this stage, all processes of mineral development, management optimization and genetic understanding (Figure 4). The resulted model (Figure 4) will constitute the basis for the integration of the proposed Systemic Approach.

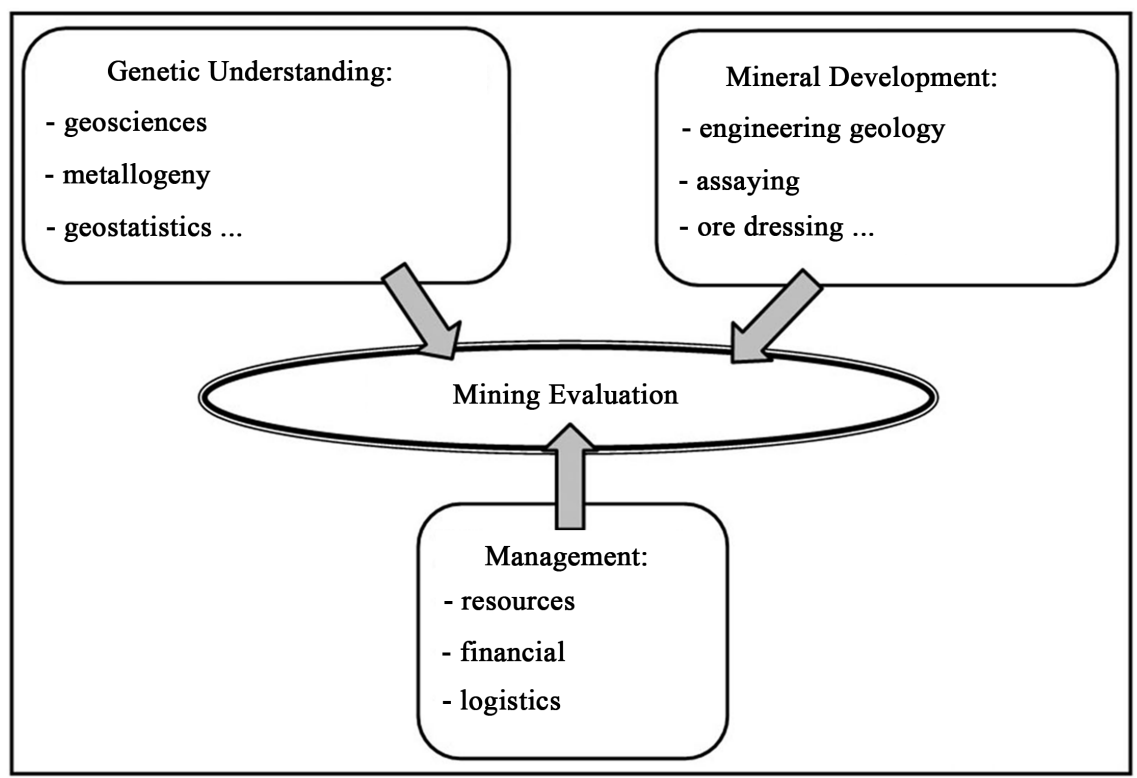

Figure 3. The keys to the success of mining valuation process: Mining characterization, genetic characterization and efficient management.

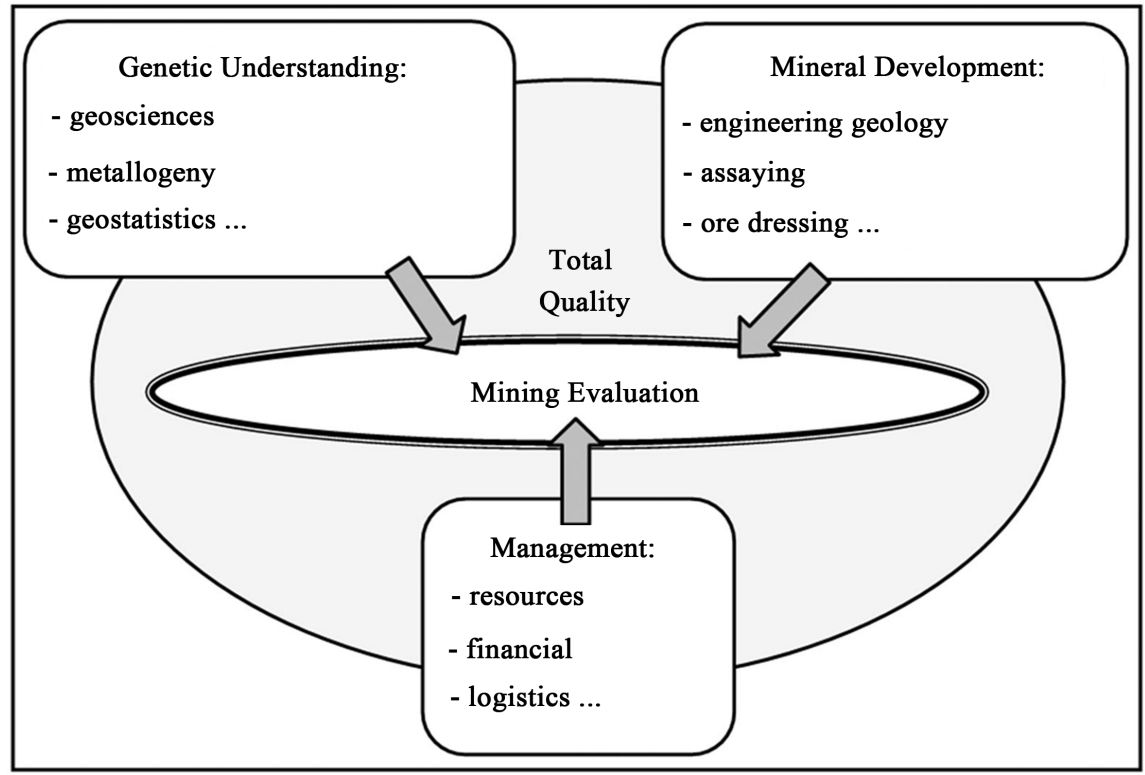

Figure 4. The keys to the success of mining valuation process: Integration of a TQMS. 


\section{The Geologic and Mining Knowledge System}

Instead of promoting a mining technology which is certainly well known by the various mining stakeholders, we would rather recommend a unifying and integrating approach, at the origin of such a technology: the Systemic Approach integrating genetic, mining and management visions. This approach is recommended to the prospector, to the operator, to the manager and to the geoscientist who must be synergistic partners within the complex and multidisciplinary process of mining evaluation.

\subsection{Expected Results of the Systemic Approach}

This Systemic Approach should lead to the design of a geological and ore models as consistent as possible with the present state of knowledge relating to the deposit. This systemic model could be named "Geologic and Mining Knowledge System (GMKS)", and to be unifying, it has to effectively integrate all the mining evaluation data composed of the three following subsystems:

1. At first, raw data (these are the facts): including attribute, metadata, morphological, geometrical, spatial data... They come from all relevant sources: geological, technical (sampling and assaying, mineral processing, civil engineering, mining methods...), socio-economic data (contents, impurities, standards, environment, safety, legislation, feasibility, economic analysis, risk analysis...), management and planning data (planning, extract costs, margins, quality control...). This will be the subsystem of data: the database.

2. When the database is operational, the system should provide data description, visualization, processing, analysis, correlation, estimation, modelling and simulation of the geological and ore properties. This must be done in space (vertical and lateral), at different scales (from atom to the deposit), in 3D and in real time. However, to be of good quality, this processing has to stay semi-automatic; i.e., calculations should be ran only after an appropriate setting of parameters, by applying context and scientific judgment and experience [11]. The results will constitute the processed data subsystem: the information base.

3. Finally, the system should have the ability to integrate to the results of the semi-automatic processing convenient expert interpretations based on professional standards, skills and experiences. The system will have to take into account both genetic and mining interpretations, and to manage the multiplicity of interpretations and models, not only explicit ones, but also a large amount of implicit ones, as defined by Nickols [12] and advised by Howard, et al. [8]. This will, then, constitute the subsystem of knowledge: the knowledge base $[11]$.

\subsection{The Concept of the Knowledge System}

To design such a system, some clarifications have to be made to avoid some confusions and amalgams harmful to the quality of the process: 
- The $G M K S$ is, at first, an information system. It must be the result of systemic analysis, design and modelling of the real-world which it is supposed to represent. Such data modelling providing the basic prerequisite of a SpatioTemporal Geoscience Information System is presented by Le, et al. [13].

- The design of this system is a project, and as such, it will have to be carried out by a Project Management team and according to the methods of Information Systems Analysis and Design, in the order to achieve project objectives, to streamline resources and to manage risks. As well, the System Analysis and the Project Management must be integrated within the TQMS to ensure the performance of the implementation process (Figure 5). The BGS, for example, has developed and implemented a Project Management System (PMS) prior to the Knowledge System implementation. This PMS provides the BGS Knowledge System by the project planning information [8]: deployed approach, methodologies, resources and expertise.

- Although the participation of information system analysts is mandatory, it is necessary to point out confusion still unfortunately frequent in our country: that to believe that they own the system, and thus, they determine the system and its design specifications.

Owners are the end-users for two reasons:

1) The system is designed for them;

2) They provide the job rules, standards and procedures.

Therefore, end-users should be involved in the design, not only passively through increasing their awareness and training them to use the system, but actively by encouraging them to make decisions concerning 1) the definition of strategic and operational needs 2) the definition of goals and 3) the choice of technological solutions. In the order to avoid any possibility of failure, end-users should also be involved actively in the process of Continuous Verification and Improvement. This can be done as part of the TQMS framework (Figure 5) during and after the system design.

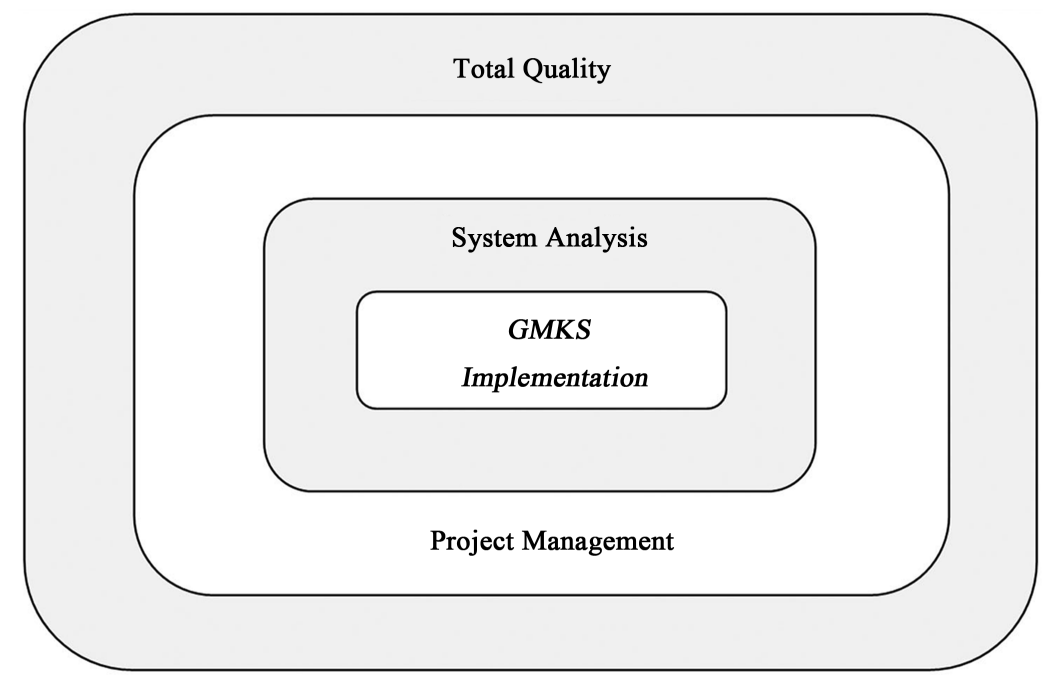

Figure 5. Conceptual framework of the implementation process of a Geologic and Mining Knowledge System (GMKS). 
- In theory, the GMKS is not a computer system and may not be computerized (implemented within a computer system). An example of non-computerized $G M K S$ is the set of data, knowledge, skills, standards and procedures mainly formalized in paper documents and organized within hard files. This analogue system would be a good GMKS if the facts (raw data), the processing results and interpretations are distinguished without ambiguity and if its organization is efficient. This was the standard for mining projects of before the computer epoch.

- In practice, GMKS are computerized. However, these digital systems have to be independent of the implemented computer systems (hardware and software): one should easily be able to transfer them from a computer system to another without loss of information.

- Some benefits of computerization, in the way to encourage knowledge to be created, enhanced, used, learned and shared are listed below:

- The effectiveness of the organization and management structure;

- The power of visualization, querying, calculation, analysis and modelling;

- The power of the system administration: e.g. safety, sharing roles, standardization, validation, integrity;

- The ability of technical integration: e.g. usage of constraining procedures and standards;

- The ability of scientific integration: supporting complex mathematical / cognitive computing and modelling;

- And, the huge possibility of integrating information from various origins and natures.

- But beware! Computerization is not always synonymous with performance, efficiency, relevance, consistency and speed. A poorly designed digital system is undoubtedly less effective than a well designed analogue system. It has often been found that when the actors in the design of information systems are not aware enough of this fact, the design of their system fails.

\subsection{Job Integration and Scientific Approach}

- The GMKS is an information system which should integrate full spatial components: position, geometry and topology [13].

- The geological objects are often modelled by complex geometric objects that have volume property (e.g. a sedimentary layer). The GMKS should therefore integrate the representation and the analysis of volumes (true 3D), at the basis of their geometrical, topological and semantic properties [13] [14] [15].

- The planning and the simulation of mining processes (exploration, development and exploitation) and geological objects, as well, evolve in time [13]. Thus, it is necessary that the GMKS integrate temporal analysis in real and in convenient time (the 4 th dimension).

- The geological and mineral objects have to be modelled by the system using their geological properties and their reciprocal relationships: e.g. stratigraphic time, internal variation, structural deformation... [11]. 
- The system could not be qualified as geologic and mining if it does not integrate job standards, methods, procedures and the tacit know-how. But, it should not impose them on the user, so as not to affect its innovation abilities. On the other hand, it is essential that the integration of those should not only be done as "best practice reference documents" [8], but should be implemented, when possible, on a functionality level of the system as "configuring best practices". That way, the system will be flexible enough to continuously integrate new "best practices" and constrained enough to ensure the use of the consensually "best practices".

- This system should be able to distinguish between different types of data and knowledge: allowing, thus, formal and unambiguous distinction 1) between observation, semi-automatic interpretation and human interpretation, and also 2) between different stages, levels or versions of interpretation. At this stage, the system will help to effectively capture the tacit know-how to guide the transformation of the implicit knowledge to the explicit one [8].

- The system has to be able to integrate, organize, manage, analyse, query, and share knowledge using standard geoscience's vocabularies, hierarchical classifications and, if applicable, ontologies [8]. Ontology-based knowledge systems are getting more effectiveness to integrate information of various types [16]. Such a system will help the translation of the tacit know-how in formal standard terms, classes and ontologies [8].

- To be able to model adequately the deposit, special attention must be given to data quality through assessment, control and improvement of their accuracy, precision, consistency, completeness and reliability. This can be accomplished by integrating data collection, data processing, data standardization and data management processes to the TQMS.

- The scientific approach should be inherent in the whole process of mining evaluation and all involved fields. It should accompany all stages of data collection, visualization, processing, analysis, correlation, estimation, modelling, simulation and interpretation. It has also to accompany the process of control, verification and validation. It should be systematic and rigorous.

- The scientific approach should have as main goal, the genetic understanding of the deposit:

- By the iterative increase of knowledge's quantity and quality,

- By the progressive quantification of knowledge's precision, accuracy and reliability,

- And also by providing systematic and rigorous procedures of observation, description, analysis and interpretation.

- During the geologic and mining data processing, if some data is missing, sparse or of bad quality, semi-automatic-quantitative-mathematical/statistical based calculations can commonly be not efficient. Qualitative interpretation and interpolation issued from geological human knowledge (tacit and implicit expertise) remains necessary to improve the quality, the precision and the accuracy of the ultimate result [11]. 


\section{Integration of the GMKS to the Mining Evaluation Process}

For a particular geologic and mining project, once properly designed through an efficient systemic analysis, the Geologic and Mining Knowledge System will be integrated to the keys to the success of the project's mining evaluation, thereby constituting the entire valuation process (Figure 6). The GMKS will receive raw data and iterative interpretations produced by the various actors of the mining project and validated by the TQMS. In return, actors will receive from the GMKS iterative processing results and analytic/synthetic information also validated by the TQMS. This cycle will optimize the genetic and mining characterization as well as the management of the project's resources and products. If all processes involved in mining valuation are optimized, the $G M K S$ will produce a geological and ore model conforming to the reality that it represents. Thus it would provide a highly competitive tool and definitely bring an added value, both scientific and socio-economic.

As a final perspective, the system would be integrated with all other managerial systems, which are good examples of integrating systems. If it is effectively done, the whole system becomes a Multicriteria Decision and Performance Management System, as described by Vallée, et al. [1].

\section{Conclusions}

The following recommendations are issued to any company, to any state promoting agency, to any research center, practicing in various fields of geology and mining and wanting to scientifically and socio-economically valuate its resources:

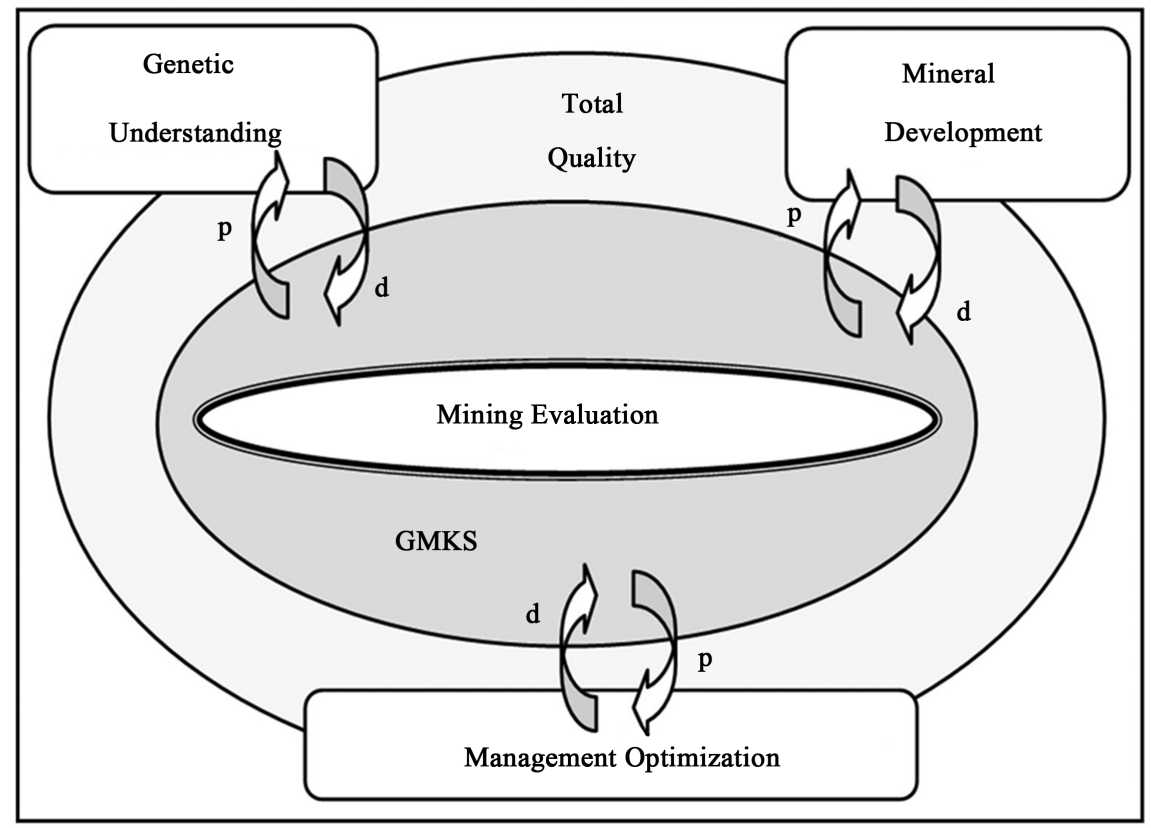

Figure 6. The keys to the success of mining valuation process: integration of a Geologic and Mining Knowledge System (GMKS). d: data and interpretations; p: processing results and synthetic information. 
- the establishment of a systematic and rigorous scientific approach to help the genetic understanding of the mineralization;

- the establishment of a Systemic Approach integrated to the design, the application, the verification and the improvement of its processes. This approach can be achieved by the implementation of an integrated Geologic and Mining Knowledge System and Total Quality Management System, both of which are excellent integrating and unifying tools.

These approaches are synergistic: the effectiveness of both established jointly is greater than the sum of effectiveness of each established individually, one helping the other to perform better. They are also synergistic with the establishment of management systems and the group could be integrated within an ultimate Management of the Performance System.

\section{Acknowledgements}

Friendly thoughts to Alferd Bogaers, Arthur Blain, Gennen McDowall and the others, which were Exploration Managers at the Anglo America Corp., for their invaluable appreciation. This article represents a fruit, among others, of an enriching collaboration within the Moroccan Exploration Project of Anglo America Corp.

Special thanks to Arthur Blain who has effectively reviewed this paper.

\section{References}

[1] Vallée, M., et al. (1992) Guide to the Evaluation of Gold Deposits. Canadian Institute of Mining, Metallurgy and Petroleum (CIM), Special Volume 45.

[2] Mchichi, M. and Moumni, A. (2004) Approches génétiques des formations phosphatées marocaines en vue d'optimiser leur prospection. First International Conference on the Valorization of Phosphates and Phosphorous Compounds (COVAPHOS 1), Marrakech, October 2004.

[3] Le Flem, G. (2004) Les phosphates du monde et le monde des phosphates. First International Conference on the Valorization of Phosphates and Phosphorous Compounds (COVAPHOS I). Marrakech, October 2004.

[4] Lacout, J.L., Oba, C.A.I. and Revel, J.C. (2004) Utilisation de phosphates marginaux brésiliens pour la fabrication d'engrais organo-phosphatés. First International Conference on the Valorization of Phosphates and Phosphorous Compounds (COVAPHOS 1), Marrakech, October 2004.

[5] Cuney, M. (2004) Facteurs contrôlant la nature et la concentration des impuretés dans les phosphates sédimentaires. First International Conference on the Valorization of Phosphates and Phosphorous Compounds (COVAPHOS 1), Marrakech, October 2004.

[6] Glaum, R. (2004) Anhydrous Phosphates of Transition Metals - Chemistry, Crystal Chemistry and Application. First International Conference on the Valorization of Phosphates and Phosphorous Compounds (COVAPHOS I), Marrakech, October 2004.

[7] Daafi, Y. and Jourani, E. (2016) Processus de traitement des données géologiques à l'OCP. Resources \& Innovative Geology, Montpellier, 4-7 April 2016.

[8] Howard, A.S., Hatton, B., Reitsma, F. and Lawrie, K.I.G. (2009) Developing a Geos- 
cience Knowledge Framework for a National Geological Survey Organisation. Computers \& Geosciences, 35, 820-835.

[9] Kessler, H., Mather, S. and Sobisch, H.-G. (2009) The Capture and Dissemination of Integrated 3D Geospatial Knowledge at the British Geological Survey Using GSI3D Software and Methodology. Computers \& Geosciences, 35, 1311-1321.

[10] Heath, C.P.M. (2003) Geological, Geophysical, and Other Technical and Soft Skills Needed by Geoscientists Employed in the North American Petroleum Industry. AAPG Bulletin, 87, 1395-1410.

[11] Turner, A.K. (2006) Challenges and Trends for Geological Modelling and Visualisation. Bulletin of Engineering Geology and the Environment, 65, 109-127.

[12] Nickols, F.W. (2000) The Knowledge in Knowledge Management. In: Woods, J.A. and Cortada, J.W., Eds., The Knowledge Management Yearbook, ButterworthHeinemann, Boston, 89-107.

[13] Le, H.H., Gabriel, P., Gietzel, J. and Schaeben, H. (2013) An Object-Relational Spatio-Temporal Geoscience Data Model. Computers \&Geosciences, 57, 104-115.

[14] Maxelon, M., Renard, P., Courrioux, G., Brändli, M. and Mancktelow, N. (2009) A Workflow to Facilitate Three-Dimensional Geometrical Modelling of Complex Poly-Deformed Geological Units. Computers \& Geosciences, 35, 644-658.

[15] Ming, J., Pan, M., Qu, H. and Ge, Z. (2010) GSIS: A 3D Geological Multi-Body Modeling System from Netty Cross-Sections with Topology. Computers \& Geosciences, 36, 756-767.

[16] Fonseca, F.T., Egenhofer, M.J., Agouris, P. and Câmara, G. (2002) Using Ontologies for Integrated Geographic Information Systems. Transactions in GIS, 6, 231-257.

\section{Submit or recommend next manuscript to SCIRP and we will provide best} service for you:

Accepting pre-submission inquiries through Email, Facebook, LinkedIn, Twitter, etc. A wide selection of journals (inclusive of 9 subjects, more than 200 journals)

Providing 24-hour high-quality service

User-friendly online submission system

Fair and swift peer-review system

Efficient typesetting and proofreading procedure

Display of the result of downloads and visits, as well as the number of cited articles

Maximum dissemination of your research work

Submit your manuscript at: http://papersubmission.scirp.org/

Or contact jgis@scirp.org 